\title{
A Model of Factors Affecting Entrepreneurial Intention among Information Technology Students in Vietnam
}

\author{
Bui Nhat VUONG ${ }^{1}$, Nguyen Ngoc Duy PHUONG ${ }^{2}$, Dao Duy HUAN ${ }^{3}$, Tran Nhu QUAN ${ }^{4}$
}

Received: May 27, 2020 Revised: June 07, 2020 Accepted: July 03, 2020

\begin{abstract}
In recent decades, the research field of entrepreneurship phenomenon has significantly increased in both quantity and sophistication. In Vietnam, paradoxically, while creating a new business venture has become a tendency, the interest in studying entrepreneurs seems not to be thoroughly investigated. This research aims to evaluate the factors that affect the entrepreneurial intention of information technology (IT) students in Vietnam. The authors make use of mixed methods including both quantitative research method and qualitative research method. The qualitative research method is employed to identify meanings, confirmations, adjustments, and compliments for concept-measurement variables in the conceptual model. Quantitative research is conducted from a sample of 424 IT senior students across many universities in Vietnam. Questionnaires have been sent to students to evaluate the measurement scale and appropriateness of the research model. Results from multiple regression highlighted five independent variables affecting the dependent variable, the entrepreneurial intention, in a descending order as following: entrepreneurial educational environment, personal characteristics, perception of feasibility, entrepreneurial supports, and financial accessibility. In addition, this research has proved that the variable attitudes towards entrepreneurship partially mediated among the interrelationship of the aforementioned variables. From this research, the authors make some recommendations to enhance entrepreneurial intentions of IT students in Vietnam.
\end{abstract}

Keywords: Entrepreneurial Intentions, Entrepreneurship, IT Students, Entrepreneurship Education, Personal Characteristics

JEL Classification Code: M12, M13, M15, M21

\section{Introduction}

Business entrepreneurship has long been regarded as one of the key strategic directions of many country in the world including Vietnam. Entrepreneurship is one of the basic solutions to foster economic growth and employments.

${ }^{1}$ First Author and Corresponding Author. Lecturer, Faculty of Air Transport, Vietnam Aviation Academy, Vietnam [Postal Address: 104 Nguyen Van Troi, Ward 8, Phu Nhuan District, Ho Chi Minh City, 700000, Vietnam] Email: nhatvuonga1@gmail.com

${ }^{2}$ International University, Ho Chi Minh City, Vietnam - Vietnam National University, Ho Chi Minh City, Vietnam.

Email: nndphuong@hcmiu.edu.vn

${ }^{3}$ Vice Rector, Nam Can Tho University, Can Tho City, Vietnam.

Email: ddhuan51@yahoo.com.vn

${ }^{4}$ Lecturer, School of Business, International University-Vietnam National University HCMC, Vietnam. Email: tnquan@hcmiu.edu.vn

(c) Copyright: The Author(s)

This is an Open Access article distributed under the terms of the Creative Commons Attribution Non-Commercial License (http://Creativecommons.org/licenses/by-nc/4.0/) which permits unrestricted noncommercial use, distribution, and reproduction in any medium, provided the original work is properly cited.
In 2010, Ho Chi Minh City set a goal to become "startup city for the youth". According to Global Startup Index (Global Entrepreneurship Monitor-GEM) Vietnam, issued by Vietnam Chamber of Commerce and Industry (VCCI) in 2019 , recognition of business opportunities has dramatically increased in comparison with that of 2018 (56.8\% in 2019 against $39.4 \%$ in 2018). The proportion of people who intend to launch their own startup in the next three years as a percentage of the Vietnamese adult population has increased from $18.2 \%$ in 2018 to $22.3 \%$ in 2019 . This figure, however, is still lower than the average of $36.5 \%$ in the developed countries. Young people (age18-35) have less cognition of business feasibility than middle-aged (age 36-64). However, the young people are more sensitive to business opportunities, more risk-seeking and more intent on startup than the middle-aged people in Vietnam $(15.5 \%$ against $11.9 \%$ ).

Vietnam is the only country among developing countries that has more than half of its population using the Internet frequently. According to experts, adopting the Internet and information technology is the shortest way to compensate 
for limitations of infrastructure and fundamentals in Vietnam in comparison with developed countries. Technology was, is being, and is going to be one of the very important aspects contributing to the development of global economy as well as Vietnam economy itself. Cultivating innovative technology and inventive industry is an inevitable trend for future advancement and modernization of our world. Ho Chi Minh Computer Association (HCA) announces that there have been 18,000 new startup businesses in Vietnam until April 2020. In this process, information technology is the field attracting many startup businesses from youngsters. The fast pace of Industrial Revolution 4.0 has facilitated rapid evolution of information technology startups in Vietnam, which act as a main driving force for the development of innovative technology products to meet the demands of social life in Vietnam. In 2017, Vietnam Genius Reward also announces many changes in criteria for IT merit awards and officially open the awards for "IT Startups".

Research on startups has drawn the attention, not only of policymakers, but also academics worldwide (Mahadalle \& Kaplan, 2017). In recent years, there was also some research on startups by millennials and students in Vietnam. However, as far as the authors are aware, there is currently no contemporary research on factors affecting information technology entrepreneurship intentions of students in Vietnam. Exploring and measuring these factors would therefore lay a foundation for planning policies to support startup environments, proposing solution to foster startup entrepreneurial spirits among students, especially in the field of information technology - an important and exigent field give the current context of Vietnam. Therefore, the research on "Factors affecting entrepreneurship intentions of information technology students in Vietnam" is a requisite to gain insights on IT startups for millennials.

\section{Theoretical Background}

This research is based on two main theories, the Theory of Planned Behavior (TPB) of Ajzen (1991) and the theory The Entrepreneurial Event (SEE) of Shapero and Sokol (1982).

\subsection{Entrepreneurship}

Entrepreneurship is a general terminology indicating a company in the incubation stage. This term is especially popular for technology companies in their conception and development stage. Entrepreneurship also implies that a business entity, be it either an individual or a group of people, explores new business opportunities or new working manners dignifying independence, constant innovations and risk-acceptance to create new values in current business contexts (Bird, 1988).

\subsection{Entrepreneurship Intentions}

According to Krueger (1993), intentions are cognitive state right before making actions and therefore intentions represent a degree of commitment to actions in the future. Shapero and Sokol (1982) reckon that people with startup intention are the pioneers in seizing contemporary and attractive business opportunity within their grasp. Startup will be commenced if an individual possesses positive attitudes, thoughts and intention toward it. A strong intention is a prerequisite for allocating efforts to build a business startup. This viewpoint is also supported by Krueger (1993) when these two authors propose that people with startup intention will accept risk and engage in necessary actions when they realize signals of business opportunities. On another hand, entrepreneurial intention of individuals also originated from the fact that they realize business opportunities and utilize the current available resources and the current ambient supports to form their own enterprise (Kuckertz \& Wagner, 2010).

\subsection{Theory of Planned Behavior - TPB}

The Theory of Planned Behavior (TPB) (Ajzen, 1991) has been developed from the Theory of Reasonable Action (TRA) of Ajzen and Fishbein (1980), with an assumption that a behavior can be predicted or explained based on behavioral tendencies to commit such behavior. Behavioral tendencies, in this case, include incentive factors that can impact behavior and are defined as a degree of efforts that people are willing to engage to make actions.

Behavioral tendencies, in turn, are a function of three factors. The first one is (1) attitude toward behavior embodying personal positive or negative appraisals on startup matters. This attitude is influenced by psychological elements and contemporary contexts. For example, a student may posessess positive attitude toward startup because his or her parents are entrepreneurs. The second factor is (2) subjective norm, also known as the opinions of surrounding people. Subjective norm is a measure of social pressure that influences the decisions to commit actions. For example, if a student knows that their friends have had hard experiences in doing business, they may be pressured against developing startup intentions. The third factor is (3) perceived behavior control reflecting individual's perception toward challenges in carrying out a behavior. Perceived behavior control includes two components, inside confidence and outside resources such as finance, time and ambient environment. Ajzen (1991) suggests that the factor perceived behavior control imposes a direct impact on the behavioral tendencies, and if an individual is right on his/her perception of control, this factor can predict an individual behavior. 


\subsection{The Entrepreneurial Event - SEE}

The model of Entrepreneurial Event of Shapero and Sokol (1982) is a classical model that has been quoted and applied in many studies on startup because of its usefulness. This theory points out that the factors of displacements and personal attitudes toward startup would influence individual's decision on building a business startup. The personal attitude encompasses individual perception on feasibility and desirability toward startups.

Situational factors: according to the model of Shapero and Sokol (1982), most individuals are resistant to situational changes until they have to make different choices. Shapero proposed that the majority of "entrepreneurial events" of individuals originated from situational factors can be divided into three groups: "negative displacements", or pushes such as immigration, divorce, job dismissal; "positive displacements", or pulls such as good financial support, appropriate strategic partners; and "between things", such as graduations and degree completion. However, the process from entrepreneurial intention to startup building is mediated by two factors - feasibility and desirability. Both factors arise from individuals' perceptions that have been shaped by their own social environment and economic conditions. In another word, once an individual regards that startup is both feasible and desirable, he/she will establish a decision to build startups.

Desirability: desirability toward startup expresses a personal thought of an individual on the attractiveness of building a startup and forms a value framework for that individual. This value framework, in turn, is influenced by the common value of community culture such as family, friends and colleagues. According to Shapero, to make individuals desirable to build startups, society has to give entrepreneurs appropriate positions and impression as well as dignify many values such as creativity, responsibility, challenge-acceptance and independence. In this way, "desirability" toward startup of Shapero and Sokol (1982) is quite similar to "positive attitudes" and "subjective norms" of Ajzen (1991).

Feasibility: situational factors and desirability are not enough to persuade an individual to build a startup. A third factor, feasibility, is thus needed as a measure toward future success of a startup. According to Shapero and Sokol (1982), external resources and supports such as financial access, informational access, preferential policies from governments and municipals, experiences of ascendants, and startup ideology; and internal factors such as skills and abilities all contributes to individual's perception of feasibility. This "feasibility" factor is quite similar to "perceived behavior control of Ajzen (1991) theory.

There are interactions between perception of feasibility and perception of desirability: if an individual perceives that building a startup is unfeasible, he/she may not feel desirable to begin that startup. The Theory of Planned Behavior (TPB) (Ajzen, 1991) in psychology research field and the theory of The Entrepreneurial Event (Shapero \& Sokol, 1982) in entrepreneurial research field have thus provided a theoretical background with sufficient concepts to carry out research on startup intentions.

In summary, the theoretical models of entrepreneurial intention has been developed and empirically tested and becomes a widely accepted methodology with decent explanatory power and high reliability. Contemporary research on entrepreneurial intention has been applied in many academic contexts. Despite different viewpoints about variables affecting startup intentions, these models allow to analyze three important factors affecting startup intentions, i.e. , personality, environment, and resources, to explain the causes leading to startup intentions. These theories are the theoretical background for the concept of "startup intentions" in this research.

\section{Hypothesis Development}

Research based on The Theory of Planned Behavior (TPB) of Ajzen (1991) and the theory of The Entrepreneurial Event of Shapero and Sokol (1982) have classified factors affecting entrepreneurial intention into two categories: the internal factors such as attitudes toward startup, perception of feasibility, and personal characteristics; and external factors such as startup supports, entrepreneurial educational environment, and financial accessibility. However, previous research did not pay much attention to students in information technology. In the current social context, information technology is an inevitable trend for development and IT also acts as a foundation for startup projects. Students in IT can master technology and are sensitive to detect business opportunities associated with new technologies and products. In reality, when technology-oriented universities open educational courses on startups, there are more technology students deciding to set up companies than students from economics-centered universities. This research also selectively pick factors to do empirical survey in Vietnam context to gain insights to underlying factors affecting Entrepreneurial intention of students in information technology. From the results of this research, the authors proposed administrative recommendations to enhance startup entrepreneurial spirits of students aligning to development orientations of Vietnam.

\subsection{Attitudes toward Entrepreneurship}

Attitudes are positive or negative appraisals, supports or objections of an individual about a planned behavior (Ajzen, 1991). In this research, attitudes toward entrepreneurship 
include appraisals, supports and objections of an individual with entrepreneurial intention toward business behavior that individual is planning for. According to Carayannis et al. (2003), business behavior is measured in two aspects: (1) personal advantage of being an entrepreneur and (2) benefits to society as an entrepreneur. Meanwhile, other research only focuses on the first aspect where attitudes are measured with respect to personal advantage of the individuals with startup intentions. Research by Karali (2013) on the affects of educational entrepreneur courses on business intentions of students in Holland measured attitudes with four variables: (1) the advantages of being an entrepreneur outweigh the disadvantage, (2) being an entrepreneur is attractive, (3) being an entrepreneur needs opportunities and resources, and (4) allowance to satisfy self-demands. In this research, the authors argued that attitudes toward entrepreneurship of Vietnamese students must be measured both in personal aspects, following the measurement scale of Karali (2013), and in conjunction with benefits to society similar Carayannis et al. (2003). Therefore, Hypothesis H1 is proposed as follows:

$\boldsymbol{H}_{I}:$ Attitudes toward entrepreneurship have positive impacts on entrepreneurship intentions of IT students.

\subsection{Perception of Feasibility}

Perception of feasibility is personal realization of easiness, hardship, controllability and constraints when an individual commits a behavior. It is also a degree of confidence on the practicability of behaviors (Ajzen, 1991). In this research, perception of feasibility is individual's feeling about his or her capability in building successful startups. Entrepreneurial intention would be impaired if the startup ideas are perceived as infeasibility. Feasibility, therefore, brings hopes and decisiveness to transform ideas into actions and products. According to the research result of Haris et al. (2016), perception of feasibility influences students' attitudes and intentions toward entrepreneurship. From these discussions, the authors introduce the following hypotheses:

$\boldsymbol{H}_{2 a}:$ Perception of feasibility has positive impacts on attitudes toward entrepreneurship of IT Students.

$\boldsymbol{H}_{2 b}$ : Perception of feasibility has positive impacts on entrepreneurship Intentions of IT Students.

\subsection{Personal Characteristics}

Personal characteristics relate to certain traits specializing prominent features of entrepreneurs. This factor has been proved to predict Entrepreneurial intention of businesspeople (Shaver \& Scott, 1992). However, unlike Shaver and Scott
(1992), attributes personal characteristics determining entrepreneurial intention to three aspects: imperative for success, internal control, and risk acceptance, among which the imperative for success reflects the desirability of a person to build rewarding businesses. In addition, internal control incarnates the degree of confidence and power of a person in controlling business behaviors and direct results from such behaviors. Khan et al. (2011) show that students with high internal control would be prudent against risks and would present high chances to become an entrepreneur. Finally, risk acceptance incorporates the readiness to face challenges and accepting consequences emanating from risks in doing startup businesses. According to Mat et al. (2015), the factor "Perception of Feasibility" has influences on attitudes and intentions toward startups. These discussions lead to the following hypotheses:

$\boldsymbol{H}_{3 a}:$ Personal characteristics have positive impacts attitudes toward entrepreneurship of IT students

$\boldsymbol{H}_{3 b}$ : Personal characteristics have positive impacts entrepreneurial Intentions of IT students.

\subsection{Entrepreneurial Supports}

Entrepreneurial supports include internal influential forces such as opinions from family, friends and colleagues; and external influential forces such as social movements (Pavlou \& Chai, 2002). From the viewpoints of Haris et al. (2016), entrepreneurial supports, especially opinions of family members, act as important roles in shaping startup intention. This influence is the most noticeable in collective cultures where personal benefits are secondary to community interests because of mutual influences among community members. In collective cultures, the subjective norms impose positive impacts on individual thoughts and attitudes. Vietnam is a country with familyoriented traditions, therefore, individual independence is not regarded as highly as in Western countries. Some studies (e.g., Giao \& Vuong, 2020; Haris et al., 2016; Mat et al., 2015; Wongnaa \& Seyram, 2014) have shown that the factor Startup Supports has influences on students' attitudes and intentions toward startups. Following these discussions, the authors put forwards two more hypotheses:

$\boldsymbol{H}_{4 a}:$ Entrepreneurial supports have positive impacts on attitudes toward entrepreneurship of IT students.

$\boldsymbol{H}_{4 b}$ : Entrepreneurial supports have positive impacts on entrepreneurial Intentions of IT students.

\subsection{Financial Accessibility}

Funding plays an important role as the backbone for many businesses and startups. A prominent issue in building 
startups that pose a challenge to students is raising funds and attracting capitals for their business ideas. Ease of financial access will facilitate startup chances and vice versa. Research results of Wongnaa and Seyram (2014) and Haris et al. (2016) show that the factor "Financial Accessibility" has influences on students' attitudes and intentions toward startups. Therefore the authors introduce the following hypotheses:

$\boldsymbol{H}_{5 a}:$ Financial accessibility has positive impacts on attitudes toward entrepreneurship of IT students.

$\boldsymbol{H}_{5 b}$ : Financial accessibility has positive impacts on entrepreneurial intentions of IT students.

\subsection{Entrepreneurial Educational Environment}

Entrepreneurial educational environment relates to courses, lectures and extracurricular activities that provide students with knowledge, skills and attitudes to pursue careers in entrepreneurship (Ooi et al., 2011; Lee \& Kim, 2019). Many empirical studies have tested the positive relationship between entrepreneurial educational environment and startup intentions. Entrepreneurial educational environment acquire students with necessary business knowledge and abilities to assemble entrepreneurial spirits to face future challenges in business world and to overcome the risk-barriers (Ekpoh \& Edet, 2011; Lu \& Wang, 2018). Therefore, entrepreneurial educational environment is an efficient and effective mean to inspire students' intentions to build startups, make business actions and enhancing risk-daring attitudes in business. Research by Wongnaa and Seyram (2014) and Haris et al. (2016) also confirm the positive relationships among entrepreneurial educational environment, attitudes toward entrepreneurship and startup intentions. Therefore, the authors propose the following hypotheses (see Figure 1):

$\boldsymbol{H}_{6 a}:$ Entrepreneurial educational environment has positive impacts on attitudes toward entrepreneurship of IT students.

$\boldsymbol{H}_{6 b^{\circ}}$ : Entrepreneurial educational environment has positive impacts on entrepreneurial intentions of IT students

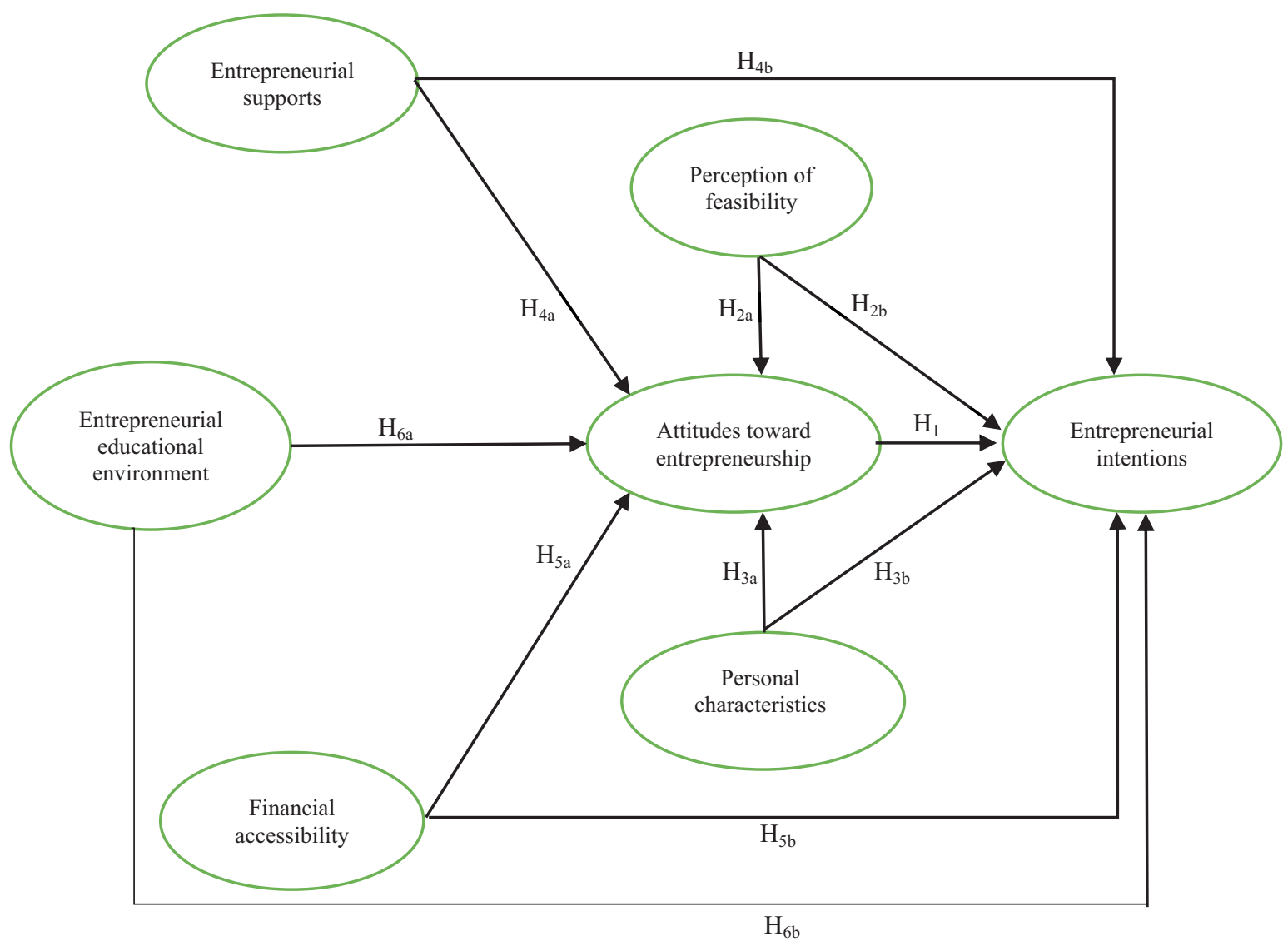

Figure 1: Research model 


\section{Research Methods}

Quantitative research aims to examine the appropriateness of measurement scales in researching entrepreneurial intentions in information technology. In addition, care has been taken to evaluate the usage of terminologies in questionnaires to clarify the meaning of each sentence before the survey is officially distributed to students in information technology universities.

The authors conducted group discussion including 14 members who are senior IT students in Ho Chi Minh University of Natural Science, Ho Cho Minh University of Technology, Ho Chi Minh University of Information Technology, Hutech University, Ton Duc Thang University, FPT University, and HUFLIT University in November 2019. The aim of this group discussion is to explore research ideas and collect more information to construct, supplement and adjust the questionnaires before conducting quantitative research. From the group discussion outlines, the students all agree that the contents are clear and easy to understand and the hints to measurement scale are sufficient. Based on contributed opinions, the survey questionnaires are constructed. After adjusting for language layout, the questionnaires are officially applied to the next phase of quantitative research.

A pilot test has been conducted on 50 senior IT students in various universities in Ho Chi Minh City to evaluate the contents and language presentation of measurement scale. An important mission in this step is making sure that the survey attendants understand the contents of each question in the survey to assure the verbal coherence and meaning clearness. The reliability of the measurement using 5-point Likert scale (1-Strongly disagree, 2-Disagree, 3-Neutral, 4-Agree, 5-Strongly agree) has also been tested to exclude obscure items and variables. Consequently, an official survey questionnaire has been shaped as the result of this process. The questionnaires are then distributed to 424 senior IT students across many universities in Vietnam. Table 1 classifies 424 survey responses based on gender and education level (see Table 1).
Table 1: Descriptive statistics on student demographics

\begin{tabular}{|l|c|c|c|}
\hline \multicolumn{2}{|c|}{$\mathbf{N}=\mathbf{4 2 4}$} & Total & Frequency \\
\hline \multirow{2}{*}{ Gender } & Female & 71 & 16.7 \\
\cline { 2 - 4 } & Male & 353 & 83.3 \\
\hline \multirow{2}{*}{$\begin{array}{l}\text { Education } \\
\text { level }\end{array}$} & University & 296 & 69.8 \\
\cline { 2 - 4 } & College & 128 & 30.2 \\
\hline
\end{tabular}

\section{Research Results}

\subsection{Reliability and Validity of Measurement Scale}

The Cronbach's Alpha reliability coefficient of measurement scale is analyzed for each variable. Items with item-total correlation less than 0.3 are excluded from the analysis. Variables with Cronbach's Alpha coefficient greater and 0.6 are accepted in the next stage of analysis (Vuong \& Giao, 2020).

Based on Table 2, Cronbach's Alpha values range from 0.836 to 0.887 . In addition, the smallest item-total correlation coefficient is 0.560 . In general, the reliability of all variables and all items is decent (Cronbach's Alpha $>0.7$ and itemtotal correlation $>0.3$ ) and, thus, confirms the authenticity of this research (Vuong \& Suntrayuth, 2020).

The validity of measurement scale is evaluated via Exploratory Factor Analysis (EFA). Reliability analysis shows that there are 30 items from seven variables reliable enough for EFA evaluation. EFA evaluation is carried out using Principal Component Analysis with Varimax rotation in Table 3.

KMO and Bartlett's test reject the hypothesis of no relationship between 30 items in the overall figure (sig. = $0.000<0.005)$. High KMO coefficient $(0.797>0.5)$ confirms the relationship among variables int his study and EFA is an appropriate analysis method. With Eigenvalue greater than 1 and principal component extraction with varimax rotations, EFA has extracted seven variables from 30 items at accumulated variance of $67.312 \%$ (greater than $50 \%$ ) (Giao, Vuong, Huan, et al., 2020). All the factor loadings are also greater than 0.5 . These facts confirm the validity of the variables studied in this research.

Table 2: Cronbach's alpha and Item-Total Correlation

\begin{tabular}{|c|c|c|c|}
\hline Thang đo & Items & Cronbach's alpha & $\begin{array}{c}\text { The minimum value of Corrected } \\
\text { item-total Correlation }\end{array}$ \\
\hline Entrepreneurial supports & 4 & 0.836 & 0.593 \\
\hline Perception of feasibility & 5 & 0.875 & 0.674 \\
\hline Entrepreneurial educational environment & 4 & 0.832 & 0.578 \\
\hline Personal characteristics & 5 & 0.822 & 0.560 \\
\hline Financial accessibility & 3 & 0.825 & 0.656 \\
\hline Attitudes toward entrepreneurship & 5 & 0.841 & 0.585 \\
\hline Entrepreneurial Intentions of IT Students & 4 & 0.887 & 0.715 \\
\hline
\end{tabular}


Table 3: Results of exploratory factor analysis

\begin{tabular}{|c|c|c|c|}
\hline Variables & Items & Coding & $\begin{array}{l}\text { Loading } \\
\text { factor }\end{array}$ \\
\hline \multirow{5}{*}{$\begin{array}{l}\text { Perception of } \\
\text { Feasibility }\end{array}$} & You believe in your success when building startup & PF2 & 0.833 \\
\hline & Building startup is easy to you & PF3 & 0.812 \\
\hline & Building startup is the best way to make use of your knowledge & PF1 & 0.780 \\
\hline & You know how to develop a business plan & PF5 & 0.753 \\
\hline & You are able to become a prosperous entrepreneur & PF4 & 0.718 \\
\hline \multirow{5}{*}{$\begin{array}{l}\text { Attitudes toward } \\
\text { Entrepreneurship }\end{array}$} & $\begin{array}{l}\text { Being an entrepreneur give you more advantages than } \\
\text { disadvantages }\end{array}$ & AE5 & 0.869 \\
\hline & You think that entrepreneurship is attractive & AE4 & 0.853 \\
\hline & You will become an entrepreneur when you have a chance & AE1 & 0.665 \\
\hline & Being an entrepreneur can satisfy your personal request & AE3 & 0.648 \\
\hline & Being an entrepreneur is a good contribution to the society & AE2 & 0.622 \\
\hline \multirow{5}{*}{$\begin{array}{l}\text { Personal } \\
\text { characteristics }\end{array}$} & You tend to choose careers that requires explorations and creativity & DDTC1 & 0.830 \\
\hline & You regard entrepreneurship as interesting and challenging & DDTC3 & 0.796 \\
\hline & You dare to face business challenge & PC5 & 0.759 \\
\hline & You can accept business risks & $\mathrm{PC} 4$ & 0.725 \\
\hline & You are able to mange an enterprise & $\mathrm{PC} 2$ & 0.703 \\
\hline \multirow{4}{*}{$\begin{array}{l}\text { Entrepreneurial } \\
\text { Supports }\end{array}$} & My family will support my decision to build startups & ES4 & 0.859 \\
\hline & My friends will support my decision to build startups & ES1 & 0.834 \\
\hline & $\begin{array}{l}\text { The people who are important to me will support me in building } \\
\text { startups }\end{array}$ & ES3 & 0.833 \\
\hline & Governments has policies to encourage students to build startups & ES2 & 0.648 \\
\hline \multirow{4}{*}{$\begin{array}{l}\text { Entrepreneurial } \\
\text { educational } \\
\text { environment }\end{array}$} & University provide knowledge on startups & EEE2 & 0.888 \\
\hline & $\begin{array}{l}\text { The main curricular courses in university acquire me enough } \\
\text { qualifications to build startups }\end{array}$ & EEE3 & 0.820 \\
\hline & $\begin{array}{l}\text { My university organizes startup-oriented activities (startup } \\
\text { competitions, startup conferences) }\end{array}$ & EEE1 & 0.780 \\
\hline & My university pays attention to develop startup skills for me & EEE4 & 0.753 \\
\hline \multirow{3}{*}{ Financial accessibility } & I can borrow from my friends and my family to build startups & FA2 & 0.883 \\
\hline & I can accumulate capital from my savings and part-time jobs & FA1 & 0.846 \\
\hline & $\begin{array}{l}\text { I can raise funds from other sources (banks and financial } \\
\text { institutions) }\end{array}$ & FA3 & 0.822 \\
\hline \multirow{4}{*}{$\begin{array}{l}\text { Entrepreneurial } \\
\text { intentions of IT } \\
\text { Students }\end{array}$} & I always determine that I will build an enterprise in the future & El4 & 0.885 \\
\hline & I will try my best to set up my enterprise & EI3 & 0.881 \\
\hline & I have seriously thought of establishing an enterprise & $\mathrm{El} 2$ & 0.870 \\
\hline & I will do my own business after graduation & El1 & 0.838 \\
\hline \multicolumn{3}{|l|}{ Eigenvalue } & 1.335 \\
\hline \multicolumn{3}{|l|}{ Accumulated variance } & 67.314 \\
\hline \multicolumn{3}{|c|}{ Kaiser-Meyer-Olkin (KMO) } & 0.797 \\
\hline
\end{tabular}




\subsection{Hypothesis Testing}

Correlation analysis has been carried out between dependent variable, entrepreneurial intentions (EI) and independent variables: Entrepreneurial supports (ES), Perception of feasibility (PF), Entrepreneurial educational environment (EEE), Personal characteristics (PC), Financial accessibility (FA) and Attitudes toward Entrepreneurship (AE). The pairwise Pearson's correlation coefficients are displayed in Table 4.

Based on Table 4, all the correlation coefficients are statistically significant and are eligible to be included in a multiple regression model. A regression model can highlight factors affecting Entrepreneurial intention of IT students. To examine the relationship between independent variables and dependent variable, the authors build two separate multiple regression models making use of all the variables together.
The regression results in Table 5 demonstrates that adjusted R2 of the first and the second model are 0.648 and 0.743 , respectively, which mean that $64.8 \%$ variation in attitudes toward entrepreneurship is explained by five independent variables and $74.3 \%$ variation in entrepreneurial intentions is explained by entrepreneurial supports, perception of feasibility, entrepreneurial educational environment, personal characteristics, financial accessibility and attitudes toward entrepreneurship. The analysis also presents two meaning F-coefficients with Sig. $=0.000(<$ 0.05 ), which confirm the appropriateness of the models given the data collected. The maximum Variance Inflated Factor (VIF) in the model is 1.668 (much less than 10), which ensure there is no multicollinearity in these models and the relationships among independent variables does not affect the explanatory power of our regression models (Giao, Vuong, \& Quan, 2020). The d-coefficient of Durbin-Watson

Table 4: Correlation analysis results

\begin{tabular}{|c|c|c|c|c|c|c|c|}
\hline & ES & PF & EEE & PC & FA & $\mathrm{AE}$ & El \\
\hline ES & 1 & $0.491^{* *}$ & $0.438^{* *}$ & $0.448^{* *}$ & 0.049 & $0.362^{* *}$ & $0.613^{* *}$ \\
\hline PF & & 1 & $0.294^{* *}$ & $0.465^{* *}$ & -0.060 & $0.277^{* *}$ & $0.744^{* *}$ \\
\hline EEE & & & 1 & $0.348^{* *}$ & -0.007 & $0.250^{* *}$ & $0.543^{* *}$ \\
\hline $\mathrm{PC}$ & & & & 1 & -0.084 & $0.269^{* *}$ & $0.594^{* *}$ \\
\hline $\mathrm{FA}$ & & & & & 1 & -0.029 & 0.035 \\
\hline$A E$ & & & & & & 1 & $0.415^{* *}$ \\
\hline El & & & & & & & 1 \\
\hline \multicolumn{8}{|c|}{$\begin{array}{l}\text { Note: }{ }^{* *} \text {. Correlation is significant at the } 0.01 \text { level (2-tailed). } \\
\text { EI = Entrepreneurial Intentions; ES = Entrepreneurial supports, PF = Perception of feasiblity, EEE = Entrepreneurial } \\
\text { educational environment, PC = Personal characteristics, FA = Financial accessibility and AE = Attitudes toward } \\
\text { Entrepreneurship. }\end{array}$} \\
\hline
\end{tabular}

Table 5: Hypothesis testing results

\begin{tabular}{|c|c|c|c|c|c|}
\hline \multirow{2}{*}{ Variable } & Model 1 & Model 2 & $\begin{array}{l}\text { Total impact (Direct } \\
\text { and Indirect) }\end{array}$ & \multirow{2}{*}{ VIF } & \multirow{2}{*}{ Conclusion } \\
\hline & $\begin{array}{l}\text { Attitudes toward } \\
\text { Entrepreneurship }\end{array}$ & $\begin{array}{l}\text { Entrepreneurial } \\
\text { Intentions }\end{array}$ & $\begin{array}{l}\text { Entrepreneurial } \\
\text { Intentions }\end{array}$ & & \\
\hline $\begin{array}{l}\text { Attitudes toward } \\
\text { Entrepreneurship }\end{array}$ & & $0.121^{* * *}$ & & 1.188 & Accepted \\
\hline Entrepreneurial Supports & $0.143^{* * *}$ & $0.130^{* * *}$ & $0.394^{* * *}$ & 1.668 & Accepted \\
\hline Perception of feasibility & $0.191^{* * *}$ & $0.088^{* * *}$ & $0.400^{* * *}$ & 1.481 & Accepted \\
\hline $\begin{array}{l}\text { Entrepreneurial educational } \\
\text { environment }\end{array}$ & $0.187^{* * *}$ & $0.144^{* * *}$ & $0.452^{* * *}$ & 1.295 & Accepted \\
\hline Personal characteristics & $0.185^{\star * \star}$ & $0.099^{* * *}$ & $0.405^{* * *}$ & 1.448 & Accepted \\
\hline Financial accessibility & $0.228^{* * *}$ & 0.08 & $0.349^{* * *}$ & 1.022 & Accepted \\
\hline Adjusted $\mathrm{R}^{2}$ & 0.648 & 0.743 & & & \\
\hline Sig. (Anova) & 0.000 & 0.000 & & & \\
\hline Durbin-Watson & 2.024 & 2.090 & & & \\
\hline
\end{tabular}


test is $2.090(1<\mathrm{d}<3)$, so we conclude that the residues are independent and there is no serial correlation among residues (Giao, Vuong, \& Tung, 2020). The analysis results support that there is no violation to assumptions of multipleregression models and thus our model is appropriate to model the factors influencing entrepreneurial intentions of IT students.

Analysis results in Table 5 confirms that attitudes toward entrepreneurship imposes positive impacts on entrepreneurial intention with $\beta=0.121$ and sig. $=0.000$. In addition, entrepreneurial supports, perception of feasibility, entrepreneurial educational environment, personal characteristics and financial accessibility also impose direct and indirect positive impacts on entrepreneurial intentions because the standardized regression coefficients of these independent variables are greater than 0.000 and are statistically significant (Sig. $<0.05)$. The degree of influences among these independent variables to entrepreneurial intentions are listed in descending order as following: entrepreneurial educational environment $\left(\beta_{3}\right.$ $=0.452)$; personal characteristics $\left(\beta_{4}=0.405\right)$; perception of feasibility $\left(\beta_{2}=0.400\right)$; entrepreneurial supports $\left(\beta_{1}=\right.$ $0.394)$, and financial accessibility $\left(\beta_{5}=0.349\right)$. However, this research also highlight that financial accessibility does not have any direct impact to entrepreneurial intentions, instead it inflicts an indirect impact through attitudes toward entrepreneurship. Therefore, the hypothesis $\mathrm{H} 5 \mathrm{~b}$ is rejected, but other hypotheses H1, H2a, H2b, H3a, H3b, H4a, H4b and $\mathrm{H} 5 \mathrm{a}$ are confirmed at $95 \%$ confidence level.

\section{Conclusions and Recommendations}

\subsection{Conclusion}

This research model has been developed based on a synthesis of theories in psychology and business fields. The research model has been tested on a sample of 424 senior IT students in different universities in Vietnam. With the findings, this research make some contributions to practical administration in Vietnam. Firstly, the Startup Intention of IT students are slightly above average with a mean value of 3.655 , therefore policymakers should find solutions to enhance Entrepreneurial intention of students in the future. Secondly, Cronbach's Alpha and Exploratory Factor Analysis have confirmed the reliability and validity of variables and items in this research, both of which can be implemented in different research. Finally, this research indicates five factors affecting entrepreneurial intention of Vietnamese students through a mediated variable Attitudes toward entrepreneurship. These factors are listed based on their relative strength of influence from the strongest to the least impact as following: Entrepreneurial educational environment; Personal Characteristics; Perception of Feasibility; Startup Supports; and Financial Accessibility (see Figure 2).

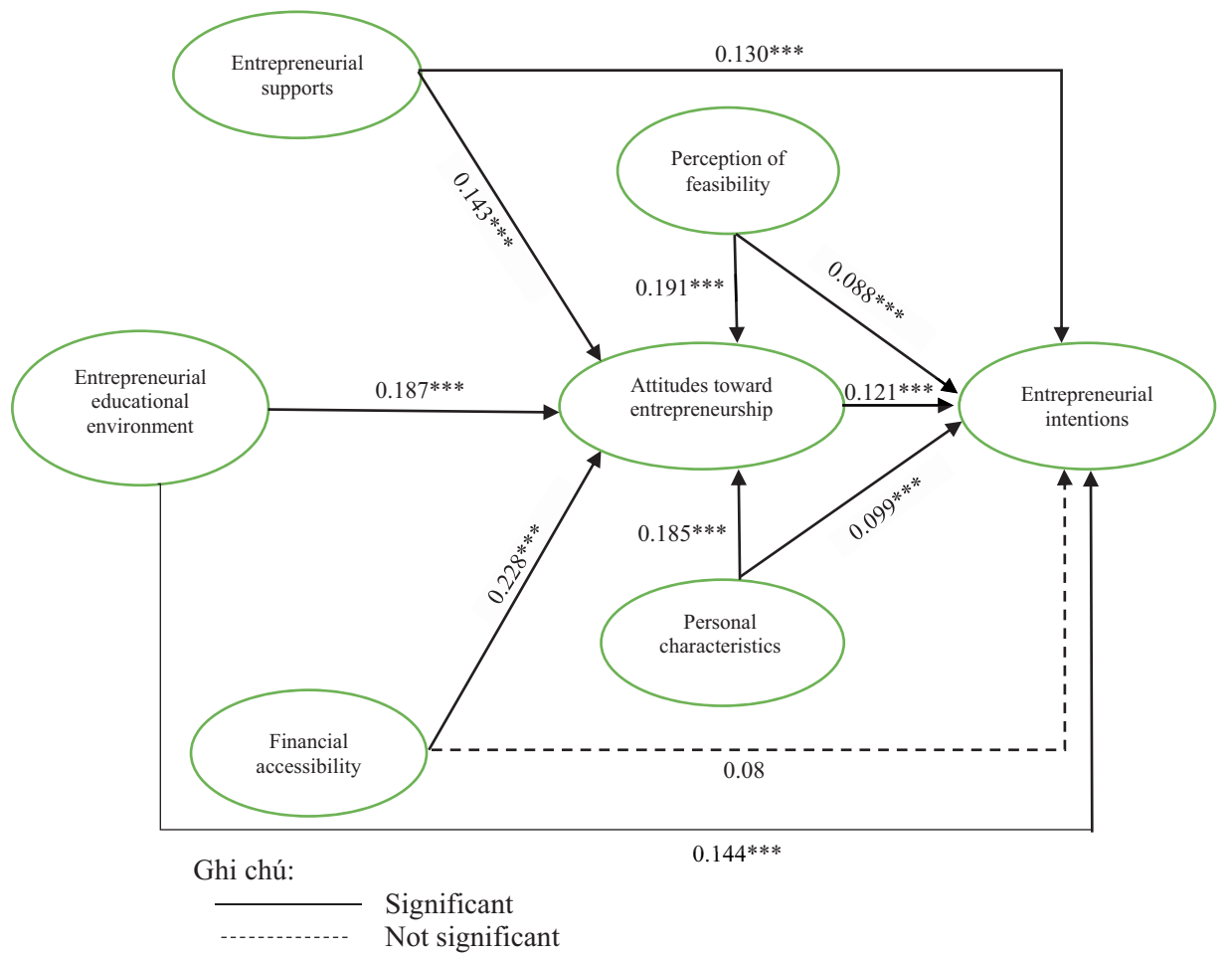

Figure 2: Research result model 


\subsection{Recommendations}

\subsubsection{Entrepreneurial Educational Environment}

The research results show that entrepreneurial educational environment is the most influential factor on entrepreneurial intention with $\beta=0.452$. Accordingly, the authors would like to make some recommendations to enhance entrepreneurial intention of IT students through educational environment. Beside the main courses, university program should be designed to adopt the demands from practical business world with more focus on entrepreneurship, management of small- and medium-sized enterprises (SMEs), intelligence property ownership, business planning process, and venturing investments. However, coursework alone is not sufficient to improve business-oriented behaviors and enhance intentions to build startups. The program should also encompass skills and ability related to innovation, activeness, confidence, decision techniques, negotiation strategies, and challengeaccepting attitudes. Concurrently, universities should organize extracurricular activities orienting toward businesses such as establishing business idea clubs and alumni and entrepreneur club; setting up business fairs, business conferences and business competitions to materialize business ideas; arranging interactions between students and entrepreneurs to foster experience sharing and inspiring. In addition, field works at company sites could also provide students with valuable skills such as group work, leadership, planning and communication.

\subsubsection{Perception of Feasibility}

The research result ranks perception of feasibility in second position with $\beta=0.405$. To enhance entrepreneurial intentions of IT students through perception of feasibility, the authors recommend that university should include more courses on business and startup beside IT courses, such as business law, corporate management, project management, financial management and leadership arts. These new courses should focus on acquiring students with knowledge and skills instead of business theory. Lecturers for these courses should be experienced practitioners and entrepreneurs to inspire the perceptions of students.

\subsubsection{Personal Characteristics}

This is the third ranking factor with $\beta=0.400$. Enhancing entrepreneurial intentions of IT student through personal characteristics requires an active approach to entrepreneurial spirits. Entrepreneurial spirits should not be confused with economics and business operations. While the latters are the fact of day-to-day activities in the business world, the former aims to boost creativities and innovations in conducting business.
Entrepreneurship is a combination of thinking, knowledge and skills. While knowledge and skills can be taught, thinking methods should be nurtured in the early time when students enter universities. Entrepreneurial thinking methods can act as a foundation for business behaviors such as risk-acceptance, independence, confidence, teamwork and leadership. University programs should integrate entrepreneurial spirits into the educational outcomes to encourage startup desirability among students. University and companies should come together to organize and sponsor entrepreneurial activities such as business idea competitions and business plan competitions. These activities could also improve student feelings on reasons and possibilities of startup ideas and thus align their personal characteristics toward business world.

\subsubsection{Entrepreneurial Support}

Entrepreneurial support is the fourth factor affecting entrepreneurial intention of IT students. Supports for students' startups could come from close cooperation among universities, companies and business associations so that students can approach, explore and represent business ideas and startup plans. In addition, university should establish startup consulting services where students can seek for advices on their startup intentions. Government should also lend a hand to stimulate Entrepreneurial intention of IT students, such as providing favorable credit lines for student startups, allowing tax reduction and tax exempts for student startups, building social programs and projects for young startups and inaugurate assisting system regarding documents and policies on startups.

\subsubsection{Financial Accessibility}

Capital is the backbone of all businesses, therefore, paving access to capital is crucial for successful startups. Friendly connections among university, alumni, practitioners and entrepreneurs could foster the establishment of startup funds that encourage students to develop startup ideas. These startup funds can raise capital for feasible startup ideas and provide informational supports on the market segments, investment process, government policy and enterprise regulations. Financial support from the government, such as favorable credit lines, tax reduction and tax shelters are also needed for early stage of students startups.

\section{Limitations and Recommendations on Future Research}

Although this research has met its prescribed objective of exploring factors affecting entrepreneurial intention 
of IT students, some limitations persist. Firstly, because this research focuses only on IT students with convenient sampling, the results many not be representative of all IT students in Vietnam. Future research should carry out probabilistic sampling in all universities with IT programs to attain higher representativeness. Secondly, future research should pay attention to the differences in entrepreneurial intention among genders and educational level. Finally, because this research can only attribute $74.3 \%$ variations in entrepreneurial intention to five independent variables and one mediated variable, there are other factors that were not yet detected in this research. Future research, therefore, should explore more factors to improve this current one.

\section{References}

Ajzen, I. (1991). The theory of planned behavior. Organizational Behavior and Human Decision Processes, 50(2), 179-211.

Ajzen, I., \& Fishbein, M. (1980). Understanding Attitudes and Predicting Social Behavior. Englewood Cliffs, NJ: PrenticeHall.

Bird, B. (1988). Implementing Entrepreneurial Ideas: The Case for Intention. The Academy of Management Review, 13(3), 442453. doi:10.2307/258091

Carayannis, E. G., Evans, D., \& Hanson, M. (2003). A crosscultural learning strategy for entrepreneurship education: outline of key concepts and lessons learned from a comparative study of entrepreneurship students in France and the US. Technovation, 23(9), 757-771. https://doi.org/10.1016/S01664972(02)00030-5

Ekpoh, U. I., \& Edet, A. O. (2011). Entrepreneurship Education and Career Intentions of Tertiary Education Students in Akwa Ibom and Cross River States, Nigeria. International Education Studies, 4, 124-137.

Giao, H. N. K., \& Vuong, B. N. (2020). Vietnamese Consumer Attitudes towards Smartphone Advertising. Journal of Asian Finance, Economics and Business, 7(5), 195-204. https://doi. org/10.13106/jafeb.2020.vol7.no5.195

Giao, H. N. K., Vuong, B. N., Huan, D. D., Tushar, H., \& Quan, T. N. (2020). The effect of emotional intelligence on turnover intention and the moderating role of perceived organizational support: Evidence from the banking industry of Vietnam. Sustainability, 12(5), 1857. https://doi.org/10.3390/su12051857

Giao, H. N. K., Vuong, B. N., \& Quan, T. N. (2020). The influence of website quality on consumer's e-loyalty through the mediating role of e-trust and e-satisfaction: An evidence from online shopping in Vietnam. Uncertain Supply Chain Management, 8(2), 351-370. https://doi.org/10.5257/j.uscm.2019.11.004

Giao, H. N. K., Vuong, B. N., \& Tung, D. D. (2020). A model of organizational culture for enhancing organizational commitment in telecom industry: Evidence from vietnam. WSEAS Transactions on Business and Economics, 17, 215-224. https://doi.org/10.37394/23207.2020.17.23
Haris, N. A., Abdullah, M., Othman, A. T., \& Rahman, F. A. (2016). Exploring the Entrepreneurial Intention Among Information Technology Students. Information Technology Journal, 22, 116-122.

Karali, S. (2013). The impact of entrepreneurship education programs on entrepreneurial intentions: An application of the theory of planned behaviour. Master Thesis. Erasmus University of Rotterdam, Rotterdam, Netherlands.

Khan, M. M., Ahmed, I., Nawaz, M. M., \& Ramzan, M. (2011). Impact of personality traits on entrepreneurial intentions of university students. Interdisciplinary Journal of Research in Business, 1(4), 51-57.

Krueger, N. (1993). The Impact of Prior Entrepreneurial Exposure on Perceptions of New Venture Feasibility and Desirability. Entrepreneurship Theory and Practice, 18(1), 5-21. doi: $10.1177 / 104225879301800101$

Kuckertz, A., \& Wagner, M. (2010). The influence of sustainability orientation on entrepreneurial intentions - Investigating the role of business experience. Journal of Business Venturing, 25(5), 524-539. https://doi.org/10.1016/j.jbusvent.2009.09.001

Lee, W.-S., \& Kim, B.-Y. (2019). The Effects of Career Orientations on Entrepreneurial Satisfaction and Business Sustainability. Journal of Asian Finance, Economics and Business, 6(4), 235248. https://doi.org/10.13106/jafeb.2019.vol6.no4.235

Lu, H., \& Wang, J. (2018). Entrepreneurial Intention of Two Patterns of Planned Behaviour and Alertness: Empirical Evidence in China. Journal of Asian Finance, Economics and Business, 5(2), 63-72. https://doi.org/10.13106/jafeb.2018.vol5.no2.63

Mahadalle, A., \& Kaplan, B. (2017). Entrepreneurial characteristics and competencies as determinants of corporate performance: a study on small enterprises in Mogadishu, Somalia. International Journal of Research, 5, 243-254.

Mat, S. C., Maat, S. M., \& Mohd, N. (2015). Identifying Factors that Affecting the Entrepreneurial Intention among Engineering Technology Students. Procedia - Social and Behavioral Sciences, 211, 1016-1022. https://doi.org/10.1016/j. sbspro.2015.11.135

Ooi, Y., K., Selvarajah, C., \& Meyer, D. (2011). Inclination towards entrepreneurship among university students: An empirical study of Malaysian university students. International Journal of Business and Social Social Science, 2(4), 206-220.

Pavlou, P., \& Chai, L. (2002). What Drives Electronic Commerce across Cultures? Across-Cultural Empirical Investigation of the Theory of Planned Behavior. Journal of Electronic Commerce Research, 3, 240-253.

Shapero, A., \& Sokol, L. (1982). The Social Dimensions of Entrepreneurship. Englewood Cliffs, NJ: Pearson PrenticeHall.

Shaver, K. G., \& Scott, L. R. (1992). Person, Process, Choice: The Psychology of New Venture Creation. Entrepreneurship Theory and Practice, 16(2), 23-46. doi:10.1177/104225879201600204

Vuong, B. N., \& Giao, H. N. K. (2020). The impact of perceived brand globalness on consumers' purchase intention and the 
moderating role of consumer ethnocentrism: An evidence from Vietnam. Journal of International Consumer Marketing, 32(1), 47-68. doi:10.1080/08961530.2019.1619115

Vuong, B. N., \& Suntrayuth, S. (2020). The impact of human resource management practices on employee engagement and moderating role of gender and marital status: An evidence from the Vietnamese banking industry. Management Science Letters, 10(7), 1633-1648. https://doi.org/10.5267/j.msl.2019.12.003

Wongnaa, C. A., \& Seyram, A. Z. K. (2014). Factors influencing polytechnic students' decision to graduate as entrepreneurs. Journal of Global Entrepreneurship Research, 4(1), Article number: 2(2014). doi:10.1186/2251-7316-2-2 